\title{
Bif-1 is overexpressed in hepatocellular carcinoma and correlates with shortened patient survival
}

\author{
RENGEN FAN $^{1,2^{*}}$, YUFENG MIAO ${ }^{3 *}$, XIANGXIANG SHAN $^{4}$, HAIXIN QIAN $^{1}$, \\ CHANGZHI SONG ${ }^{5}$, GUANGZHOU $\mathrm{WU}^{6}$, YAN CHEN ${ }^{2}$ and WENZHANG ZHA ${ }^{2}$ \\ ${ }^{1}$ Department of General Surgery, The First Affiliated Hospital of Soochow University, Suzhou 215006; \\ Departments of ${ }^{2}$ General Surgery, ${ }^{3}$ Medical Oncology, ${ }^{4}$ Geraeology, ${ }^{5}$ Orthopaedics, and ${ }^{6}$ Thoracic Surgery, \\ Yancheng City No.1 People's Hospital, Yancheng 224001, P.R. China
}

Received October 22, 2011; Accepted December 21, 2011

DOI: $10.3892 / 01.2012 .562$

\begin{abstract}
Bax-interacting factor-1 (Bif-1) interacts with Beclin1 [the mammalian ortholog of yeast autophagy-related gene 6 (Atg6)] and affects the formation of autophagosomes during autophagy. The aim of this study was to explore Bif-1 expression and its prognostic significance in comparison with various clinicopathological predictors of survival. Bif-1 protein expression was determined by immunohistochemistry in 206 hepatocellular carcinomas. Cytoplasmic immunoreactivity was scored semi-quantitatively. The results were analyzed in correlation with various clinicopathological characteristics, including patient survival. The Chi-square test and Kaplan-Meier survival analysis were applied. The expression of Bif-1 was significantly higher in the hepatocellular cancers than in the adjacent matched non-tumor tissues (51.5 vs. $33.0 \%, \mathrm{P}<0.01$ ). Increased expression of Bif-1 in hepatocellular carcinomas was significantly correlated with a low grade of differentiation and a shortened overall survival $(\mathrm{P}<0.05)$. No significant differences were found between the expression of Bif-1 and age, gender, tumor size, damage of capsule, expression of hepatitis B surface antigen (HBs$\mathrm{Ag}$ ) and portal venous invasion. Our data demonstrated that Bif-1 is frequently expressed in hepatocellular carcinoma. Overexpression of Bif- 1 is a new independent prognostic marker, which is associated with poor differentiation as well as shortened overall survival.
\end{abstract}

Correspondence to: Professor Haixin Qian, Department of General Surgery, The First Affiliated Hospital of Soochow University, Suzhou 215006, P.R. China

E-mail: fanrengen2011@qq.com

*Contributed equally

Abbreviations: Bif-1, Bax-interacting factor-1; HCC, hepatocellular carcinoma; Atg, autophagy-related genes

Key words: Bax-interacting factor-1, autophagy, hepatocellular carcinoma

\section{Introduction}

Worldwide, hepatocellular carcinoma (HCC) is the fifth most prevalent human tumor, the third cause of cancer-related mortality and a major indication for liver transplantation (1-3). Thus, HCC constitutes a major health problem and its relevance is expected to increase in the near future. Although diagnostic and surgical approaches have made great progress in recent years, patient survival remains unsatisfactory due to a high incidence of recurrence following hepatic resection or other types of locoregional therapy (4). However, the mechanisms underlying the development of $\mathrm{HCC}$ remain unclear.

Bax-interacting factor-1 (Bif-1) is an evolutionarily conserved cytoplasmic protein that contains a C-terminal SH3 domain, and was originally discovered as a Bax-binding protein. The protein does not share any other significant homology with members of the Bcl-2 family of proteins. This family of proteins interacts physically with the Bax protein and affects cell life and death $(5,6)$. Recently, the clinicopathological role of Bif-1 expression has been associated with progression or prognosis in various neoplasms (7-12). However, the clinicopathological relevance of Bif- 1 in HCC remains unknown.

The aim of this study was to examine the expression of Bif-1 in HCC and to investigate its prognostic relevance by immunohistochemical analyses.

\section{Materials and methods}

Immunohistochemical staining and evaluation. Immunohistochemical staining was carried out using the primary antibody to human Bif-1 (monoclonal, Imgenex, San Diego, CA, USA; 1:500 dilution). The sections were dewaxed through xylene and ethanol. Following the blocking of endogenous peroxidase and antigen retrieval (microwave heating in a citrate buffer for $40 \mathrm{~min}$ ), the sections were exposed to the primary antibody at $48^{\circ} \mathrm{C}$ overnight and stained using a streptavidin-biotin-peroxidase kit (Nichirei, Tokyo, Japan). The labeled antigen was then visualized by 3,3'-diaminobenzidine tetrahydrochloride, followed by counterstaining with hematoxylin. Interlobular bile duct was considered to be an internal positive control (13). 


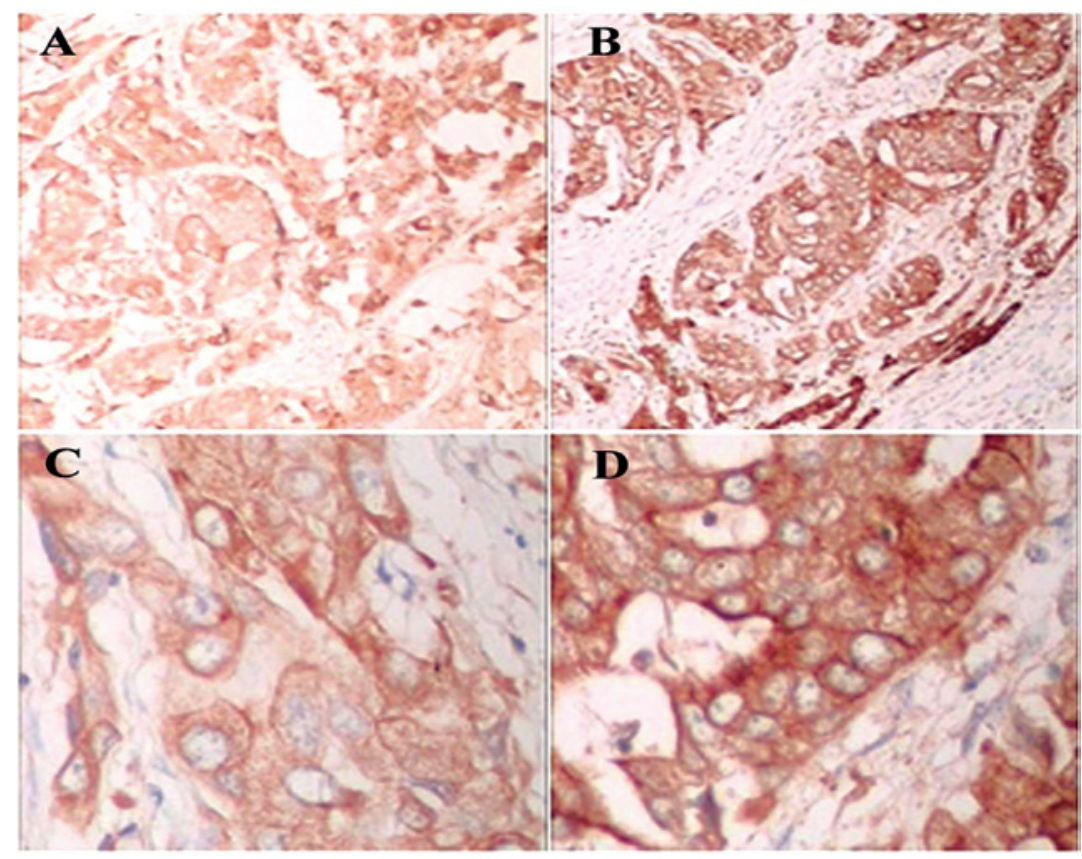

Figure 1. Immunohistochemical staining of Bif-1 in HCC and non-tumor tissues. (A) Weak expression of Bif-1 (EnVision; original magnification, x100). (B) Strong expression of Bif-1 (EnVision; original magnification, x100). (C) Weak expression of Bif-1 (EnVision; original magnification, $\mathrm{x} 400)$. (D) Strong expression of Bif-1 (EnVision; original magnification, x400). Bif-1, Bax-interacting factor-1; HCC, hepatocellular carcinoma.

Each section undergoing immunohistochemical staining for Bif-1 was evaluated within the tumor by three clinical pathologists who were unaware of patient outcome. The various results were unified by consensus. The immunoreactivity of Bif-1 was evaluated according to the intensity and percentage of positively stained cells. The percentage of positively stained cells was graded as: grade $0,0-39 \%$; grade $1,40-69 \%$ and grade $2,>70 \%$. The immunostaining intensity was scored as: 0 , negative; 1 , weak; and 2 , strong. In addition, an immunoreactive score was calculated by the addition of the percentage score of the positively stained cells and staining intensity score (0-4). The tumors with an immunoreactive score of 0-1 were designated 'low', and the tumors with an immunoreactive score of 2-4 were designated 'high'.

Statistical analysis. The Chi-square test was adopted to determine the differences among the intergroup variables by use of the SPSS 15.0 software (SPSS, Chicago, IL, USA). A Kaplan-Meier survival analysis was used to examine the correlation between the categorical groups and survival for univariate analysis. $\mathrm{P}<0.05$ was considered to indicate a statistically significant difference.

The study complied with current ethical policies of Yancheng City No.1 People's Hospital, China.

\section{Results}

Expression of Bif-1 in HCC. Immunohistochemical assays were performed on 206 patients with HCC and their matched non-tumor tissues in the same section. In normal hepatic tissues and cancer tissues, Bif-1 expression was observed as dot-like staining in the cytoplasm of cancer cells, whereas it was not detected in the nuclei of cancer cells. The representative
Table I. Correlation between various clinicopathological parameters and Bif- 1 expression in 206 HCC patients.

\begin{tabular}{|c|c|c|c|c|}
\hline \multirow[b]{2}{*}{ Patients } & \multirow[b]{2}{*}{$\begin{array}{l}\text { No. of } \\
\text { cases }\end{array}$} & \multicolumn{2}{|c|}{ Bif-1 expression } & \multirow[b]{2}{*}{ P-value } \\
\hline & & Low & High & \\
\hline Gender & & & & 0.529 \\
\hline Male & 134 & 62 & 72 & \\
\hline Female & 72 & 38 & 34 & \\
\hline Age (years) & & & & 0.286 \\
\hline$<55$ & 65 & 28 & 37 & \\
\hline$>55$ & 141 & 72 & 69 & \\
\hline Tumor size (cm) & & & & 0.345 \\
\hline$<5$ & 152 & 78 & 74 & \\
\hline$>5$ & 54 & 22 & 28 & \\
\hline Tumor differentiation & & & & $0.034^{\mathrm{a}}$ \\
\hline Well/moderate & 140 & 78 & 62 & \\
\hline Poor/undifferented & 66 & 22 & 44 & \\
\hline Capsule & & & & 0.846 \\
\hline Intact & 90 & 43 & 47 & \\
\hline Damaged & 116 & 57 & 59 & \\
\hline HBs-Ag & & & & 0.377 \\
\hline Negative & 104 & 46 & 58 & \\
\hline Positive & 102 & 54 & 48 & \\
\hline Portal venous invasion & & & & 0.375 \\
\hline None & 158 & 64 & 74 & \\
\hline Invaded & 68 & 36 & 32 & \\
\hline
\end{tabular}

${ }^{\mathrm{a}} \mathrm{P}<0.05$; Chi-square test; Bif-1, Bax-interacting factor-1; HCC, hepatocellular carcinoma; Hbs-Ag, hepatitis B virus surface antigen. 


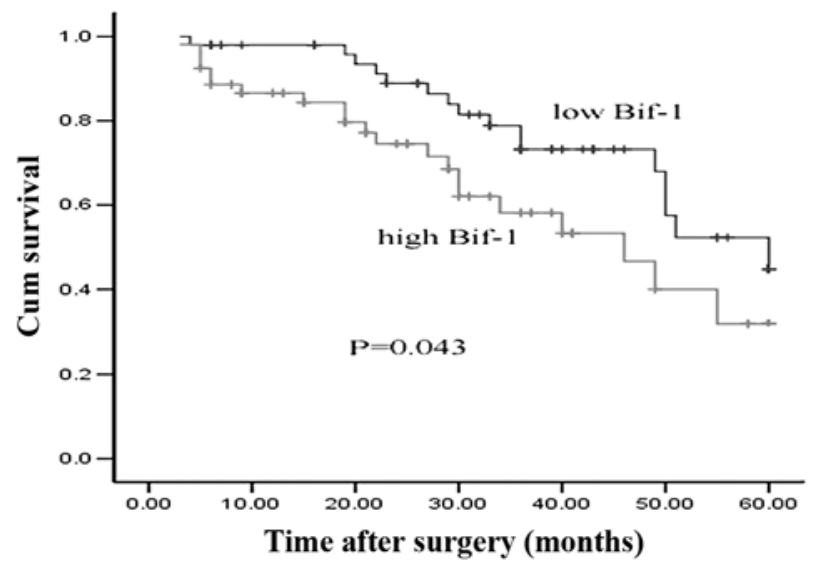

Figure 2. The post-operative survival of patients with $\mathrm{HCC}$ according to Bif-1 expression. The survival curves of the HCC patients with high and low Bif-1 scores were plotted using Kaplan-Meier analysis and their difference was evaluated by the log-rank test. Survival was measured from the date of surgery to the date of the last follow-up or mortality. A significant difference was found in the overall survival ratio between the two groups $(\mathrm{P}=0.043)$. Bif-1, Bax-interacting factor-1; HCC, hepatocellular carcinoma.

immunohistochemical results are shown in Fig. 1. In total, 106 tumors $(51.5 \%)$ were classified into the high Bif- 1 expression group. The remaining 100 tumors (48.5\%), with a constant low Bif-1 immunoreactivity, were classified as the low expression group. The high Bif-1 expression rates for the cancer and non-cancer tissues were 51.5 and $33.0 \%$, respectively, which indicates a statistically significant difference $(\mathrm{P}<0.01)$.

Correlation between clinicopathological parameters and expression of Bif-1 in HCC. Table I shows the correlation between the various clinicopathological parameters and Bif-1 expression. No significant differences were noted between the low and high Bif-1 expression groups with regard to age, gender, stage, tumor size, damage of capsule, expression of HBs-Ag and portal venous invasion. However, a significant difference was observed for tumor differentiation (well/moderate versus poor/undifferentiation, $\mathrm{P}<0.05$ ) between the two groups.

Bif-1 expression and survival in HCC. Univariate survival analyses were performed to investigate a possible prognostic impact of Bif-1 in colorectal cancers. There was a significant survival difference for patients whose tumors demonstrated high Bif-1 immunoreactivity compared with those patients whose tumors demonstrated low Bif-1 immunoreactivity (log-rank test=4.096, $\mathrm{P}=0.043$; Fig. 2). The median survival in the high expression group was 40 months, whereas that in the low expression group was 49 months. This revealed that the Bif-1 expression level was an independent prognostic factor for overall survival.

\section{Discussion}

In the present study, we examined Bif-1 expression in HCC using immunohistochemistry. The results revealed that Bif-1 is highly expressed in numerous HCC cells, compared with non-cancer tissues.

Bif-1 has been shown to interact with Beclin1 (the mammalian ortholog of yeast Atg6) through UVRAG (ultraviolet irradiation resistant-associated gene) to regulate the activation of the class III PI3 kinase, PI3KC3 (also known as Vps34), and the induction of autophagy in mammalian cells (14). Downregulation of Bif-1 significantly inhibits PI3KC3 activation and the formation of autophagosomes in HeLa cells and mouse embryonic fibroblasts (MEFs) (14).

In addition, Bif-1 has been found to co-localize with Atg9-positive vesicles (15); the formation and trafficking of these vesicles are necessary for the biogenesis and expansion of autophagosomal membranes during the induction of autophagy (16-18).

Autophagy is an evolutionarily highly conserved catabolic pathway that degrades cellular macromolecules and organelles (19-21). It is modulated by the Atg genes that control the formation of autophagosomes; cytoplasmic vesicles with a double membrane surrounding a cargo. Autophagy has received much attention in connection with programmed cell death; autophagic death. Autophagic death eliminates damaged and harmful cells, including cancer cells treated with chemotherapy drugs $(22,23)$.

Proliferating tumor cells require nutrients for growth (24). However, the tumor environment is characterized by reduced levels of oxygen and nutrients. It has been indicated that the median level of oxygen and glucose in normal breast tissue is $10 \mathrm{kPa}$ and $5 \mathrm{~mm}$, respectively, compared to $4 \mathrm{kPa}$ and $0-2 \mathrm{~mm}$ in breast cancer tissue (25). This discrepancy demonstrates that tumor cells, in addition to high level of glycolysis, also increase autophagy for energy supply (19). As tumors grow, cancer cells may require autophagy to survive in the nutrientstarved and low oxygen microenvironment, particularly in the central area of the tumors, which often exhibits limited vascularization (27-29). Autophagosomes were identified in areas of the carcinoma that were insufficiently vascularized and metabolically stressed (29). In addition, the prevention of the autophagic response in apoptosis-compromised tumor tissues leads to necrotic cell death (30). Thus, autophagy is considered to be an essential physiological reaction, which sustains cell viability under nutrient-deficient conditions (31).

In the present study, we found that poorly differentiated HCCs demonstrate a higher expression of Bif-1 compared to well-differentiated HCCs $(\mathrm{P}<0.05)$. The mechanism underlying the correlation between an increased Bif-1 expression and grading in HCC is not clear at present. Ogier-Denis et al have shown that autophagic sequestration was reduced in the undifferentiated colon cancer cell line HT29, compared to well-differentiated cells and thus leads to a high potential of autophagic protein degradation (32). We suggest that poor/undifferentiated cancer cells exhibit a more active autophagic sequestration, which is responsible for protein degradation and fosters tumor cells to survive in unfavorable, nutrient-limiting conditions.

Our results suggest that Bif-1 functions as an oncogene rather than as a tumor suppressor gene in HCC. However, previous studies have shown that Bif- 1 exhibits a reduced expression in pancreatic ductal adenocarcinoma, colorectal adenocarcinoma, prostate cancer, urinary bladder cancer, gallbladder cancer and gastric carcinoma (ACDEF). This appears to be contrary to our HCC data, in which we found a significantly shortened survival time in patients whose tumors exhibited a high Bif-1 expression. The discrepancy between the above-mentioned findings 
has yet to be explained. We presume that autophagy could play a variety of pathophysiological roles in carcinogenesis and tumor progression, and that its role may vary within the tumor cell type due to differences in the characteristics of the tumor cells and the microenvironment of the tumor tissue.

In conclusion, our findings show that Bif-1 protein expression as a new prognostic marker for HCC. The patients with overexpression of Bif-1 exhibited poor grading and a shortened survival. More studies are required to clarify the biological role of Bif-1 in order to estimate its potential value for the diagnosis and treatment of HCC.

\section{Acknowledgements}

This study was partly supported by the Department of Pathology of the Fourth Affiliated Hospital of Nantong University.

\section{References}

1. Ercolani G, Grazi GL, Ravaioli M, et al: Liver resection for hepatocellular carcinoma on cirrhosis: univariate and multivariate analysis of risk factors for intrahepatic recurrence. Ann Surg 4: 536-543, 2003

2. Bosch FX, Ribes J and Borras J: Epidemiology of primary liver cancer. Semin Liver Dis 3: 271-285, 1999.

3. Llovet JM, Burroughs A and Bruix J: Hepatocellular carcinoma. Lancet 9399: 1907-1917, 2003.

4. Arii S, Tanaka J, Yamazoe Y, et al: Predictive factors for intrahepatic recurrence of hepatocellular carcinoma after partial hepatectomy. Cancer 4: 913-919, 1992.

5. Pierrat B, Simonen M, Cueto M, Mestan J, Ferrigno P and Heim J: SH3GLB, a new endophilin-related protein family featuring an SH3 domain. Genomics 2: 222-234, 2001.

6. Cuddeback SM, Yamaguchi H, Komatsu K, et al: Molecular cloning and characterization of Bif-1. A novel Src homology 3 domain-containing protein that associates with Bax. J Biol Chem 23: 20559-20565, 2001.

7. Coppola D, Helm J, Ghayouri M, Malafa MP and Wang HG: Down-regulation of Bax-interacting factor 1 in human pancreatic ductal adenocarcinoma. Pancreas 3: 433-437, 2011.

8. Schlauder SM, Calder KB, Khalil FK, Passmore L, Mathew RA and Morgan MB: Bif-1 and Bax expression in cutaneous merkel cell carcinoma. J Cutan Pathol 1: 21-25, 2009.

9. Coppola D, Khalil F, Eschrich SA, Boulware D, Yeatman T and Wang HG: Down-regulation of Bax-interacting factor-1 in colorectal adenocarcinoma. Cancer 10: 2665-2670, 2008.

10. Coppola D, Oliveri C, Sayegh Z, Boulware D, Takahashi Y, Pow-Sang J, Djeu JY and Wang HG: Bax-interacting factor-1 expression in prostate cancer. Clin Genitourin Cancer 2: 117-121, 2008.

11. Kim SY, Oh YL, Kim KM, Jeong EG, Kim MS, Yoo NJ and Lee SH: Decreased expression of Bax-interacting factor-1 (Bif-1) in invasive urinary bladder and gallbladder cancers. Pathology 6 : 553-557, 2008.

12. Lee JW, Jeong, EG, Soung YH, Nam SW, Lee JY, Yoo NJ and Lee SH: Decreased expression of tumour suppressor Baxinteracting factor-1 (Bif-1), a Bax activator, in gastric carcinomas. Pathology 4: 312-315, 2006.
13. Iguchi T, Aishima S, Taketomi A, et al: Fascin overexpression is involved in carcinogenesis and prognosis of human intrahepatic cholangiocarcinoma: immunohistochemical and molecular analysis. Hum Pathol 2: 174-180, 2009.

14. Takahashi Y, Coppola D, Matsushita N, et al: Bif-1 interacts with Beclin 1 through UVRAG and regulates autophagy and tumorigenesis. Nat Cell Biol 10: 1142-1151, 2007.

15. Takahashi Y, Meyerkord CL and Wang HG: BARgaining membranes for autophagosome formation: regulation of autophagy and tumorigenesis by Bif-1/Endophilin B1. Autophagy 1: 121-124, 2008.

16. Noda T, Kim J, Huang WP, et al: Apg9p/Cvt7p is an integral membrane protein required for transport vesicle formation in the Cvt and autophagy pathways. J Cell Biol 3: 465-480, 2000.

17. Yamada T, Carson AR, Caniggia I, et al: Endothelial nitric-oxide synthase antisense (NOS3AS) gene encodes an autophagy-related protein (APG9-like2) highly expressed in trophoblast. J Biol Chem 18: 18283-18290, 2005.

18. Young AR, Chan EY, Hu XW, et al: Starvation and ULK1dependent cycling of mammalian Atg9 between the TGN and endosomes. J Cell Sci 18: 3888-3900, 2006.

19. Levine B and Klionsky DJ: Development by self-digestion: molecular mechanisms and biological functions of autophagy. Dev Cell 4: 463-477, 2004.

20. Høyer-Hansen M and Jaattela M: AMP-activated protein kinase: a universal regulator of autophagy? Autophagy 4: 381-383, 2007.

21. Meijer AJ and Codogno P: Signalling and autophagy regulation in health, aging and disease. Mol Aspects Med 5-6: 411-425, 2006.

22. Kirkegaard K, Taylor MP and Jackson WT: Cellular autophagy: surrender, avoidance and subversion by microorganisms. Nat Rev Microbiol 4: 301-314, 2004.

23. Kondo Y, Kanzawa T, Sawaya R and Kondo S: The role of autophagy in cancer development and response to therapy. Nat Rev Cancer 5: 726-734, 2005.

24. Cuervo AM: Autophagy: in sickness and in health. Trends Cell Biol 2: 70-77, 2004.

25. Scriven P, Brown NJ, Pockley AG and Wyld L: The unfolded protein response and cancer: a brighter future unfolding? J Mol Med 4: 331-341, 2007.

26. Moreno-Sánchez R, Rodríguez-Enríquez S, Marín-Hernández A and Saavedra E: Energy metabolism in tumor cells. Febs J 6: 1393-1418, 2007.

27. Kato K, Ogura T, Kishimoto A, Minegishi Y, Nakajima N, Miyazaki M and Esumi H: Critical roles of AMP-activated protein kinase in constitutive tolerance of cancer cells to nutrient deprivation and tumor formation. Oncogene 39: 6082-6090, 2002.

28. Pouyssegur J, Dayan F and Mazure NM: Hypoxia signalling in cancer and approaches to enforce tumour regression. Nature 7092: 437-443, 2006.

29. Degenhardt K, Mathew R, Beaudoin B, et al: Autophagy promotes tumor cell survival and restricts necrosis, inflammation, and tumorigenesis. Cancer Cell 1: 51-64, 2006.

30. White $\mathrm{E}$ : Role of the metabolic stress responses of apoptosis and autophagy in tumor suppression. Ernst Schering Found Symp Proc 4: 23-34, 2007.

31. Chen N and Karantza-Wadsworth V: Role and regulation of autophagy in cancer. Biochim Biophys Acta 9: 1516-1523, 2009.

32. Ogier-Denis E, Houri JJ, Bauvy C and Codogno P: Guanine nucleotide exchange on heterotrimeric Gi3 protein controls autophagic sequestration in HT-29 cells. J Biol Chem 45: 28593-28600, 1996. 